\title{
BIOAKTIVITAS MINYAK ATSIRI DAUN BANDOTAN (Ageratum conyzoides) TERHADAP RESPON FISIOLOGIS (GLUKOSA DARAH DAN TACHIVENTILASI) IKAN KOI (Cyprinus carpio)
}

\section{BIOACTIVITY ESSENTIAL OIL OF BANDOTAN LEAF (Ageratum conyzoides) ON KOI (Cyprinus carpio) PHYSIOLOGICAL RESPONSES (BLOOD GLUCOSE AND TACHIVENTILATION)}

\author{
Laksmi Sulmartiwi, Mardiah Rahma Umami, Moch. Amin Alamsjah dan Sri Subekti \\ Fakultas Perikanan dan Kelautan Universitas Airlangga \\ Kampus C Mulyorejo - Surabaya, 60115 Telp. 031-5911451
}

\begin{abstract}
Koi (C. carpio) is one of famous ornamental fish in Indonesia. Fish often be subject of change or stessor like physical, chemical and biology on culture. Stress in fish caused released cortisol hormone and cathecolamine hormone. Cathecolamine increase glicogenolisis, cardiovascular regulation and respiration fungtion. Blood glucose and tachiventilation (opercular movement) can indicate stress respon in fish. Essential oil of $A$. conyzoides have central analgesic activity. Analgesic drugs in vertebrae can reduce stress in fish. Essential oil shown inhibitory effect of GABA transminase, an enzime GABA (gammaaminobutryic acid) degradation which can provoking sedation. Sedation effect in fish reduce blood glucose and tachiventilation. Potency bioactive essential oil of bandotan leaf compound haven't been know in aquaculture. The potency based of $\mathrm{LC}_{50}$ (Lethal Consentration $50 \%$ ) value

Purpose of this research determined effect of essential oil Ageratum conyzoides leaf on Koi (Cyprinus carpio) Phsycology Response (Blood Glucose and Tachiventilation) every 4 hours durung 24 hours and $\mathrm{LC}_{50} 24$ hours. Research was conducted at Laboratory of Faculty of Fisheries and Marine Airlangga University Surabaya. Research design used Completely Randomized Design and followed by Duncan's Multiple range test.

Results of analysis of variance (ANAVA) from early observation and every 4 hours during 24 hours day showed that each treatment of essential oil Ageratum conyzoides leaf gave a significantly different effect on the blood glucose and tachiventilation $(\mathrm{P}<0.05)$. The highest average of blood glucose was found in D treatment at second observation $(443,67 \mathrm{mg} / \mathrm{dl})$ and the lowest was found in $C$ treatment $(60,67 \mathrm{mg} / \mathrm{dl})$. The highest average of tachiventilation was found in D treatment at first observation (1730 bit/9 minute) and the lowest was found in A treatment (437,67 bit/9 minute) at early observation. $\mathrm{LC}_{50}-24$ hours essenial oil Ageratum conyzoides leaf is 34,047 ppm. Based on measurements of water quality, treatments was still viable and good to supported viability of Cyprinus carpio during research, water temperature range between $29-31^{\circ} \mathrm{C}$, range of dissolved oxigen 4-6 mg/l, $\mathrm{pH}$ ranges 7,5-8,3 and 0,006$0,27 \mathrm{mg} / \mathrm{l}$ on ammonia.
\end{abstract}

Keywords : Ageratum conyzoides, Cyprinus carpio, $\mathrm{LC}_{50}-24$ hours, Blood Glucose, Tachiventilation

\section{Pendahuluan}

Koi (Cyprinus carpio) merupakan salah satu ikan hias yang sejak dulu hingga saat ini terkenal di masyarakat, khususnya pencinta ikan hias dan pebisnis yang terjun langsung memelihara koi dan mengomersialkannya. Pada kondisi budidaya, ikan sering menjadi subyek terhadap perubahan atau stresor seperti handling, kepadatan, transportasi dan perubahan kualitas air (Kubilay and Ulukoy, 2002). Stres pada ikan menyebabkan pelepasan hormon kortisol dan katekolamin. Kortisol mengaktifkan proses glikogenolisis dan glukoneogenesis pada ikan. Hormon katekolamin tersebut selanjutnya meningkatkan proses glikogenolisis, mengatur kardiovaskular dan fungsi pernafasan (Porchaz et al., 2009). Evans and Claiborne (2006) menyatakan bahwa ikan yang mengalami stres dapat dilihat melalui meningkatnya tachiventilasi (buka tutup operkulum ikan) dan kadar glukosa darah. Minyak atsiri daun bandotan (Ageratum conyzoides) memiliki aktivitas central analgesic (Almeida et al., 2001). Pada bidang perikanan, untuk mengurangi stres pada ikan masih digunakan obat anastesi dan sedative atau obat analgesik yang digunakan pada hewan vertebrata (Neiffer and Stamper, 2009). Minyak atsiri menunjukkan efek penghambatan GABA transminase, suatu enzim yang mendegradasi 
GABA (gamma-aminobutryic acid) dimana proses penghambatan enzim tersebut akan menimbulkan efek sedasi (Almeida et al., 2009). Efek sedasi akan menurunkan glukosa darah dan tachiventilasi pada ikan (Neiffer and Stamper, 2009). Penelitian bioaktivitas minyak atsiri daun bandotan belum dilakukan sehingga potensi bioaktif minyak atsiri daun bandotan belum diketahui terutama pada bidang perikanan. Potensi bioaktivitas tersebut didasarkan pada nilai $\mathrm{LC}_{50}$ (Lethal Concentration $50 \%$ ) yaitu konsentrasi senyawa yang dapat membunuh 50\% hewan uji (Pasaribu, 2009).

Tujuan dari penelitian ini adalah :

Mengetahui pengaruh pemberian minyak atsiri daun bandotan terhadap respon fisiologis (glukosa darah dan tachiventilasi) ikan koi (Cyprinus carpio).

Mengetahui $\mathrm{LC}_{50}$-24 jam minyak atsiri daun bandotan (Ageratum conyzoides) terhadap ikan koi (Cyprinus carpio).

Hasil penelitian ini diharapkan dapat memberikan informasi ilmiah mengenai potensi penggunaan minyak atsiri daun bandotan (Ageratum conyzoides) terhadap ikan koi (Cyprinus carpio), respon fisiologis pada ikan tersebut serta sebagai dasar pengembangan penelitian selanjutnya mengenai potensi minyak atsiri daun bandotan dalam bidang perikanan.

\section{Materi dan Metode}

Penelitian ini dilakukan di Laboratorium Fakultas Perikanan dan Kelautan, Universitas Airlangga, Surabaya. Ekstraksi minyak atsiri daun bandotan dilakukan di Laboratorium Kimia Organik di Departemen Kimia Fakultas Sains dan Teknologi Universitas Airlangga Surabaya. Penelitian ini dilaksanakan pada bulan Februari-April 2013.

Metode yang digunakan dalam penelitian ini adalah metode eksperimen, yaitu mengadakan percobaan untuk melihat suatu hasil. Perlakuan yang diberikan berupa perbedaan konsentrasi minyak atsiri daun bandotan yang diberikan, yang meliputi, perlakuan K (tanpa penambahan minyak atsiri), perlakuan A (minyak atsiri dengan konsentrasi $10 \mathrm{ppm}$ ), perlakuan B (minyak atsiri dengan konsentrasi $20 \mathrm{ppm}$ ), perlakuan C (minyak atsiri dengan konsentrasi $30 \mathrm{ppm}$ ), perlakuan D (minyak atsiri dengan konsentrasi 40 ppm), perlakuan E (minyak atsiri dengan konsentrasi $50 \mathrm{ppm}$ ), perlakuan $\mathrm{F}$ (minyak atsiri dengan konsentrasi $60 \mathrm{ppm}$ ), perlakuan $\mathrm{G}$ (minyak atsiri dengan konsentrasi $70 \mathrm{ppm}$ ), perlakuan $\mathrm{H}$ (minyak atsiri dengan konsentrasi 80 ppm), dan perlakuan I (minyak atsiri dengan konsentrasi 90 ppm)

Ekstraksi Minyak Atsiri

Pada tahap awal dilakukan penyulingan minyak atsiri daun bandotan. Penyulingan dilakukan dengan cara destilasi uap daun bandotan kering yang diremas dengan perbandingan jumlah antara air dan daun adalah 1:5. Minyak atsiri yang mengapung diatas komponen uap air kemudian diekstraksi dengan heksan dengan perbandingan 2:1 kemudian dikocok dalam corong pisah dan diulang sebanyak 3 kali (Bouda et al, 2001; Tripathi et al, 2007). Hasil pengocokan kemudian didiamkan dan diambil bagian supernatannya. Bagian tersebut kemudian diuapkan heksannya dengan alat rotary vacum evaporator sehingga terpisah antara minyak atsiri dan heksan dengan suhu $35 \square \mathrm{C}$ dengan tekanan $550 \mathrm{mmHg}$ (Sani dkk., 2012).

Persiapan Penelitian

Persiapan penelitian yang dilakukan adalah menyeleksi ikan dengan ukuran $5-7 \mathrm{~cm}$ (Laili, 2007). Setelah dilakukan seleksi ikan berdasarkan ukuran, aklimatisasi dan dipuasakan selama sehari sebelum penelitian. Wadah plastik dan akuarium yang akan digunakan dicuci hingga bersih, wadah plastik dan akuarium tersebut diisi dengan air tawar dan diberi minyak atsiri konsentrasi yang berbeda pada masing-masing perlakuan.

Pengukuran Glukosa Darah

Pengambilan sampel darah ikan koi dilakukan dengan memotong bagian caudal penduncle menggunakan gunting bedah. Pengukuran kadar glukosa darah ikan koi dilakukan dengan glucosemeter One Touch Horizon. Jumlah ikan koi yang digunakan sebanyak 25 ekor dengan ukuran $5-7 \mathrm{~cm}$. Kepadatan tiap wadah sebesar 3 ekor /1,5 liter (Laili, 2007). Wadah yang digunakan adalah wadah plastik dengan ukuran panjang $37,5 \mathrm{~cm}$, lebar $30 \mathrm{~cm}$ dan tinggi $12 \mathrm{~cm}$.

Perhitungan Tachiventilasi

Perhitungan tachiventilasi dilakukan dengan menghitung jumlah operkulum membuka dan menutup dengan menggunakan handcounter. Perhitungan tachiventilasi menggunakan ikan koi dengan jumlah sebanyak 10 ekor dengan ukuran 5-7 cm. Kepadatan ikan koi pada tiap wadah sebesar 3 ekor/1,5 liter (Laili, 2007). Wadah yang digunakan adalah wadah plastik dengan ukuran panjang $37,5 \mathrm{~cm}$, lebar $30 \mathrm{~cm}$ dan tinggi $12 \mathrm{~cm}$.

Penentuan Lethal Concentrate 50 ( $\left.\mathrm{LC}_{50} 24 \mathrm{jam}\right)$

Penentuan Lethal Concentrate 50

( $\mathrm{LC}_{50}$ - 24 jam) menggunakan ikan koi dengan jumlah sebanyak 10 ekor dengan ukuran $5-7 \mathrm{~cm}$ 
dan kepadatan tiap wadah sebesar 3 ekor/1,5 liter (Laili, 2007). Wadah yang digunakan adalah akuarium berukuran panjang dan lebar sebesar $15 \mathrm{~cm}$ serta tinggi sebesar $25 \mathrm{~cm}$. Nilai $\mathrm{LC}_{50-2} 24$ jam diperoleh dari data mortalitas ikan koi dari perlakuan yang diolah menggunakan analisis probit dengan program SPSS ver. 32 for windows (Marlinda, 2012). Data mortalitas dihitung dengan rumus (Hasnah dan Nasril, 2009):

$$
\mathrm{P}_{0}=\frac{\mathrm{r}}{\mathrm{N}} \times 100 \%
$$

Keterangan:

$\mathrm{P}_{0} \quad$ : Mortalitas

$\mathrm{r} \quad$ : Jumlah hewan uji yang mati

n : Jumlah hewan uji awal

Pengambilan Data

Pengambilan data glukosa darah dilakukan pada awal perlakuan dan setiap 4 jam selama 24 jam. Pengambilan data tachiventilasi dilakukan dengan menghitung jumlah membuka dan menutupnya operkulum dengan cara sampling pada tiap satuan percobaan (Sanjaya, 2011). Perhitungan tachiventilasi dilakukan pada awal pengamatan selama 9 menit, dan dilanjutkan pengamatan setiap 4 jam selama 24 jam (Sulmartiwi dkk., 2009). Penentuan nilai $\mathrm{LC}_{50}-24$ jam diperoleh dari data mortalitas ikan koi dari perlakuan yang diolah menggunakan analisis probit dengan program SPSS ver.32 for windows (Marlinda, 2012).

Analisa Data

Data yang diperoleh untuk perhitungan tachiventilasi dan pengukuran glukosa darah ikan diolah dengan menggunakan ANOVA (Analysis of Variance) dan dilanjutkan dengan uji jarak berganda Duncan. Data mortalitas ikan koi dianalisa dengan analisis probit dengan program SPSS untuk menentukan $\mathrm{LC}_{50}-24$ jam.

\section{Hasil Dan Pembahasan}

Hasil analisa mortalitas ikan koi selama 24 jam diperoleh kematian ikan koi keseluruhan terjadi pada perlakuan $50 \mathrm{ppm}$ hingga 90 ppm. Kematian ikan koi juga terjadi pada konsentrasi 20, 30 dan 40 ppm. Persentase kematian ikan koi dapat ditunjukkan pada Tabel 1.

Tabel 1. Data persentase mortalitas ikan koi \pm SD selama penelitian

\begin{tabular}{|c|c|}
\hline Konsentrasi (ppm) & Mortalitas $(\%) \pm$ SD \\
\hline 0 & $0 \pm 0$ \\
10 & $0 \pm 0$ \\
20 & $13,33 \pm 2,31$ \\
30 & $20 \pm 3,46$ \\
40 & $53,33 \pm 1,15$ \\
50 & $100 \pm 0$ \\
60 & $100 \pm 0$ \\
70 & $100 \pm 0$ \\
80 & $100 \pm 0$ \\
90 & $100 \pm 0$ \\
\hline
\end{tabular}

Data mortalitas yang diperoleh diolah dengan analisis probit menggunakan program SPSS untuk menentukan besar lethal concentration $50 \%$ selama 24 jam $\left(\mathrm{LC}_{50}-24\right.$ jam). Hasil analisis probit dengan program SPSS ver. 32 for windows diperoleh konsentrasi lethal concentration $50 \%\left(\mathrm{LC}_{50}-24\right.$ jam) sebesar 34,047 ppm dengan nilai konsentrasi batas terendah sebesar 28,036 ppm dan batas tertinggi 39,863 ppm. Berdasarkan analisis tersebut, terdapat korelasi antara pemberian miyak atsiri daun bandotan terhadap mortalitas ikan koi.

Rata-rata kadar glukosa darah selama penelitian dapat dilihat pada Tabel 2 dan Gambar 1.

Hasil analisis varian (ANAVA) yang dilakukan mulai awal pengamatan hingga pengamatan empat jam keenam menunjukkan bahwa setiap perlakuan pemberian minyak atsiri bandotan memberikan pengaruh yang berbeda nyata terhadap glukosa darah dari Cyprinus carpio $(\mathrm{p}<0,05)$. Pada perlakuan D terjadi kematian ikan sebesar $100 \%$ pada pengamatan 4 jam ke-3 sehingga data glukosa darah tidak diperoleh. 
Tabel 2. Rata-rata glukosa darah ikan koi selama penelitian \pm SD

\begin{tabular}{|c|c|c|c|c|c|}
\hline \multirow{2}{*}{$\begin{array}{c}\text { Pengamatan } \\
4 \text { jam ke- }\end{array}$} & \multicolumn{5}{|c|}{ Perlakuan (ppm) } \\
\cline { 2 - 6 } & $\mathrm{K}$ & $\mathrm{A}$ & $\mathrm{B}$ & $\mathrm{C}$ & $\mathrm{D}$ \\
\hline 0 & $100^{\mathrm{c}} \pm 1$ & $149,33^{\mathrm{a}} \pm 1,52$ & $107,33^{\mathrm{b}} \pm 1,52$ & $89,33^{\mathrm{d}} \pm 1,52$ & $71,33^{\mathrm{e}} \pm 3,21$ \\
1 & $139,3^{\mathrm{e}} \pm 3,21$ & $276^{\mathrm{d}} \pm 5,29$ & $291,6^{\mathrm{c}} \pm 5,03$ & $336^{\mathrm{b}} \pm 2,64$ & $380,3^{\mathrm{a}} \pm 1,52$ \\
2 & $68^{\mathrm{d}} \pm 2$ & $336^{\mathrm{b}} \pm 3,60$ & $229^{\mathrm{c}} \pm 3$ & $336,3^{\mathrm{b}} \pm 2,51$ & $443,67^{\mathrm{a}} \pm 3,51$ \\
3 & $139,3^{\mathrm{d}} \pm 2,51$ & $352^{\mathrm{a}} \pm 3$ & $205,67^{\mathrm{c}} \pm 3,51$ & $256^{\mathrm{b}} \pm 3$ & $.0000^{\mathrm{e}} \pm .00000$ \\
4 & $115,3^{\mathrm{d}} \pm 1,52$ & $224,6^{\mathrm{b}} \pm 1,52$ & $249^{\mathrm{a}} \pm 2$ & $167,6^{\mathrm{c}} \pm 1,52$ & $.0000^{\mathrm{e}} \pm .00000$ \\
5 & $115,33^{\mathrm{a}} \pm 1,52$ & $104,67^{\mathrm{b}} \pm 4,50$ & $94^{\mathrm{c}} \pm 3,60$ & $89,66^{\mathrm{c}} \pm 3,05$ & $.0000^{\mathrm{d}} \pm .00000$ \\
6 & $97^{\mathrm{c}} \pm 2$ & $103,7^{\mathrm{b}} \pm 3,51$ & $110,67^{\mathrm{a}} \pm 2,08$ & $60,667^{\mathrm{d}} \pm 3,78$ & $.0000^{\mathrm{e}} \pm .00000$ \\
\hline
\end{tabular}

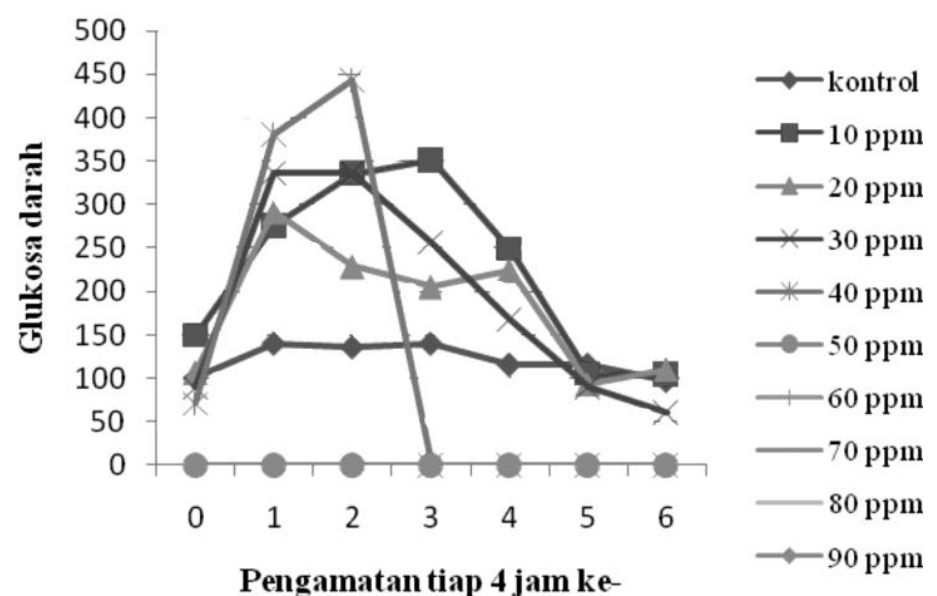

Gambar 1. Grafik rata-rata glukosa darah selama penelitian

Tabel 3. Rata-rata tachiventilasi

\begin{tabular}{|c|c|c|c|c|c|}
\hline \multirow{2}{*}{$\begin{array}{c}\text { Pengamatan } \\
4 \text { jam ke- }\end{array}$} & $\mathrm{K}$ & $\mathrm{A}$ & $\mathrm{B}$ & $\mathrm{C}$ & $\mathrm{D}$ \\
\cline { 2 - 6 } & $1792^{\mathrm{a}} \pm 199,59$ & $437,67^{\mathrm{c}} \pm 4,04$ & $1247,7^{\mathrm{b}} \pm 137,95$ & $1203,3^{\mathrm{b}} \pm 8,73$ & $1159,3^{\mathrm{b}} \pm 4,93$ \\
0 & $1477^{\mathrm{b}} \mathrm{b} \pm 83,80$ & $1243,3^{\mathrm{d}} \pm 20,55$ & $1347,7^{\mathrm{c}} \pm 52,63$ & $1538,7^{\mathrm{b}} \pm 1,52$ & $1730^{\mathrm{a}} \pm 65,81$ \\
2 & $1502,3^{\mathrm{a}} \pm 49,50$ & $1316^{\mathrm{b}} \pm 19$ & $1366^{\mathrm{ab}} \pm 182,39$ & $1253,3^{\mathrm{bc}} \pm 20,22$ & $1315,7^{\mathrm{c}} \pm 143,5$ \\
3 & $1435^{\mathrm{a}} \pm 99,41$ & $123^{\mathrm{ab}} \pm 9,96$ & $1192^{\mathrm{a}} \pm 67,02$ & $1176,7^{\mathrm{ab}} \pm 2,08$ & $771,33^{\mathrm{b}} \pm 668,02$ \\
4 & $1510,3^{\mathrm{a}} \pm 290,05$ & $1316,3^{\mathrm{a}} \pm 10,11$ & $1226,7^{\mathrm{a}} \pm 102,79$ & $1235^{\mathrm{a}} \pm 4,58$ & $825,3^{\mathrm{a}} \pm 714,93$ \\
5 & $1328^{\mathrm{a}} \pm 159,80$ & $119,1^{\mathrm{a}} \pm 9,84$ & $1313,7^{\mathrm{a}} \pm 146,37$ & $1318^{\mathrm{a}} \pm 8,50$ & $879^{\mathrm{a}} \pm 761,37$ \\
6 & $1205,3^{\mathrm{a}} \pm 147,89$ & $1063,3^{\mathrm{a}} \pm 4,04$ & $1292,7^{\mathrm{a}} \pm 107,93$ & $1256^{\mathrm{a}} \pm 2$ & $811^{\mathrm{a}} \pm 702,49$ \\
\hline
\end{tabular}

\section{Tachiventilasi}

Rata-rata kadar glukosa darah selama penelitian dapat dilihat pada tabel 2 dan gambar 2.

Hasil analisis varian (ANAVA) yang dilakukan mulai awal pengamatan hingga pengamatan empat jam kedua menunjukkan bahwa setiap perlakuan pemberian minyak atsiri bandotan memberikan pengaruh yang berbeda nyata terhadap tachiventilasi dari Cyprinus carpio $(\mathrm{p}<0,05)$. Pada pengamatan ketiga hingga keenam menunjukkan bahwa setiap perlakuan pemberian minyak bandotan tidak memberikan pengaruh yang berbeda nyata terhadap tachiventilasi dari ikan koi (Cyprinus carpio) $(\mathrm{p}<0,05)$.

Kisaran data kualitas air selama penelitian ditunjukkan pada Tabel 3. 
Tabel 4. Kisaran parameter kualitas air

\begin{tabular}{|l|c|}
\hline \multicolumn{1}{|c|}{ Parameter } & Kisaran \\
\hline Oksigen terlarut (mg/l) & $4-6$ \\
Ammonia $(\mathrm{mg} / \mathrm{l})$ & $0,006-0,27$ \\
$\mathrm{Suhu}\left({ }^{\circ} \mathrm{C}\right)$ & $29-31$ \\
$\mathrm{pH}$ & $7,5-8,4$ \\
\hline
\end{tabular}

Penentuan potensi senyawa bioaktif tersebut berdasarkan atas nilai $\mathrm{LC}_{50}$ (Lethal Concentration 50\%) yaitu konsentrasi senyawa yang dapat membunuh 50\% hewan uji. Hasil pengolahan data mortalitas ikan koi dengan analisis probit diperoleh konsentrasi lethal concentration $50 \% \quad\left(\mathrm{LC}_{50}-24\right.$ jam $)$ atau konsentrasi yang dapat membunuh $50 \%$ populasi sebesar 34,047 ppm.

Mortalitas pada ikan koi tersebut diduga disebabkan oleh senyawa toksik yang terkandung pada minyak atsiri daun bandotan. Kelimpahan komponen terpen dalam minyak atsiri bersifat toksik pada ikan (Servizi et al., (1976) dalam Andrews and Spence (1980)). Kadar glukosa dengan perlakuan pemberian minyak atsiri daun bandotan menunjukkan nilai rata-rata yang lebih tinggi dibandingkan dengan rata-rata glukosa kontrol (tanpa pemberian minyak atsiri daun bandotan) hingga akhir penelitian. Kadar glukosa yang tinggi diduga disebabkan tingginya hormon kortisol dan katekolamin akibat stresor kimia berupa pemberian minyak atsiri daun bandotan. Seyle (1936) dalam Porchaz et al., (2009) menyatakan bahwa 6 hingga 48 jam setelah organisme mengalami kondisi yang merugikan akan terjadi perubahan kimia pada darah (peningkatan kortisol), dimana kondisi tersebut disebut general alarm reaction (GAR). Komponen kimia darah akan kembali normal (general adaption syndrome) dengan melakukan beberapa perubahan pada metabolisme. Pemberian minyak atsiri daun bandotan memberikan pengaruh pada tachiventilasi. Tachiventilasi dengan perlakuan pemberian minyak atsiri daun bandotan menunjukkan nilai rata-rata yang lebih rendah dibandingkan dengan rata-rata tachiventilasi kontrol (tanpa pemberian minyak atsiri daun bandotan). Minyak atsiri menunjukkan efek penghambatan GABA transminase, suatu enzim yang mendegradasi GABA (gamma-aminobutryic acid) dimana proses penghambatan enzim tersebut akan menimbulkan efek sedasi (Almeida et al., 2009). Efek sedasi akan menurunkan glukosa darah dan tachiventilasi pada ikan (Neiffer and Stamper, 2009). Pemberian minyak atsiri daun bandotan tidak berpengaruh pada kualitas air selama penelitian. Kualitas air pada perlakuan pemberian minyak atsiri tidak mengalami perbedaan dibandingkan dengan kualitas air tanpa pemberian minyak atsiri daun bandotan. Pemberian minyak atsiri tidak mempengaruhi kelarutan oksigen. Secara umum kadar oksigen terlarut sebesar $6 \mathrm{mg} / \mathrm{l}$ sesuai dengan kadar oksigen yang mendukung bagi kelangsungan hidup ikan C. Carpio (Assareh, 2012).

\section{Kesimpulan}

Kesimpulan yang diperoleh dari penelitian ini adalah terdapat pengaruh terhadap pemberian minyak atsiri daun bandotan terhadap peningkatan glukosa darah dan penurunan tachiventilasi pada ikan koi. Konsentrasi lethal concentration $50 \%\left(\mathrm{LC}_{50}-24\right.$ jam) minyak atsiri daun bandotan terhadap ikan koi sebesar 34,047 ppm.

Minyak atsiri daun bandotan dapat dijadikan sebagai kandidat bahan sedative untuk mengurangi stres pada ikan koi sehingga dapat dimanfaatkan secara berkelanjutan dalam bidang perikanan.

\section{Daftar Pustaka}

Almeida, R.N., D.S. Navaro and J.M. BarbosaFilho. 2001. Plants with Central Analgesic Activity. Phytomedicine 8(4): 310-322.

Almeida, R.N., D.A.M. Araújo,J. C. R. Gonc,alves, F. C. Montenegro, D. P. De Sousa, J. R. Leite, R. Mattei, M. A. C. Benedito,J. G. B. de Carvalho, J. S.Cruz, J.G.Soares. 2009. Rosewood oil induced sedation and inhibition compound action potential in rodents. Journal of Ethnopharmacology 124: 440-443.

Andrews, R.E. and K. D. Spencer. 1980. Action of Douglas Fir Tussock Moth Larvae and Their Microflora on Dietary Terpenes. Applied and Environtmental Microboiology, 40 (6): 959-963.

Assareh, R., M.M.N. Shamoushaki, H.F.Langroodi and A.K. Ravari. 2012. Effect of Starvation Periode on Growth Performances and Survival of Cyprinus carpio (Linnaeus, 1758). Jurnal of Research in Biologi 2 (5): 418-423

Bouda, H., L.A. Tapon Djou, D.A Fontem, M.Y.D, Gumed Zoe. 2001. Effect of Essential Oils from Leaves of Ageratum conyzoides, Lantana camara and Cromolaena odorata on The Mortality of Sithopilus zeamais (coloptera, curculionidae). Journal of 
Stored Products Research 37(2001):193-199.

Evans, D.H. and J.B. Claiborne. 2006. The Physiology of Fishes, Third Edition. CRC Press, Taylor and Francis Group : Florida. Hal. 319-322.

Hasna dan Nasril. 2009. Efektivitas Ekstrak Buah Mengkudu (Morinda citrifolia L.) Terhadap Mortalitas Plutella xylostella L. Pada Tanaman Sawi. J. Florantek 4: 29-40.

Kubilay, A. and G. Ulukoy. 2002. The Effect of Acute Stress on Rainbow Trout (Oncorhyncus mykiss). Turk J Zool, 26: 249.

Laili, Ulfatul. 2007. Pengaruh Pemberian Ekstrak Temulawak (Curcuma xanthorrhiza Roxb) Terhadap Prevalensi dan Kelulushidupan Ikan Mas (Cyprinus carpio) yang Diinfeksi Bakteri Aeromonas hydrophyla. Skripsi. Fakultas Sain dan Teknologi. Universitas Islam Negeri Malang. Malang. 24 hal.

Marlinda, M., M.S. Sangi, A.D. Wuntu. 2012. Analisis Senyawa Metabolit Sekunder dan Uji Toksisitas Ekstrak Etanol Biji Buah Alpukat (Persea americana Mill.). Jurnal MIPA UNSRAT Online 1 (1): 24-28.

Neiffer, D.L. and M.A. Stemper. 2009. Fish Sedation, Anesthesia, Analgesia, and Euthanasia: Considerations, Methods, and Types of Drugs. ILAR Journal Vol.50 (4): 343-360.

Pasaribu, S.P. 2009. Uji Boaktivitas Metabolit Sekunder dari Daun Tumbuhan Babandotan (Ageratum conyzoides L.). Jurnal Kimia Mulawarman, VI (2): 2329.
Porchaz, M.M, L.R.M. Cordova and R.R.Enriquez. 2009. Cortisol and Glucose: Reliable Indocators of Fish Stress?. Pan American Journal of Aquatic Sciences, 4 (2): 158-178.

Sani, N.S., R. Rachmawati dan Mahfud. 2012. Pengambilan Minyak Atsiri dari Melati dengan Metode Enfleurasi dan Ekstraksi Pelarut Menguap. Jurnal Teknik POMITS Vol.1 (1): 1-4.

Sanjaya, Y. 2011. Pengaruh Kosentrasi Larutan Daun Bandotan (Ageratum conyzoides) Terhadap Tingkat Kelulusan dan Buka Tutup Operkulum Benih Ikan Koi (Cyprinus carpio) dalam Transportasi Sistem Tertutup. Skripsi. Fakultas Perikanan dan Kelautan. Universitas Airlangga. Surabaya. v, 24 hal.

Sulmartiwi, L., D.N. Chotimah. W. Tjahjaningsih. T.V. Widiyanto dan J. Triastuti. 2009. Respon Daya Cerna dan Respirasi Benih Ikan Mas (Cyprinus carpio) Pasca Transportasi Dengan Menggunakan Daun Bandotan (Ageratum conyzoides) Sebagai Bahan Antimetabolik. Jurnal Ilmiah Perikanan dan Kelautan I (1): 79-86.

Tripathy. P., N.K. Dubey, A.K. Shukla. 2008. Use of Shome Essential Oils at PostHarvest Botanical Fungicides in the Management of Grey Mould of Grapes Caused by Botry Cinerea. Word J. Microbial Biotech 